\title{
Gene expression analysis reveals that Delta/Notch signalling is not involved in onychophoran segmentation
}

\author{
Ralf Janssen $^{1}$ (D) Graham E. Budd ${ }^{1}$ \\ Received: 6 September 2015 / Accepted: 9 February 2016/Published online: 2 March 2016 \\ (C) The Author(s) 2016. This article is published with open access at Springerlink.com
}

\begin{abstract}
Delta/Notch (Dl/N) signalling is involved in the gene regulatory network underlying the segmentation process in vertebrates and possibly also in annelids and arthropods, leading to the hypothesis that segmentation may have evolved in the last common ancestor of bilaterian animals. Because of seemingly contradicting results within the well-studied arthropods, however, the role and origin of $\mathrm{Dl} / \mathrm{N}$ signalling in segmentation generally is still unclear. In this study, we investigate core components of $\mathrm{Dl} / \mathrm{N}$ signalling by means of gene expression analysis in the onychophoran Euperipatoides kanangrensis, a close relative to the arthropods. We find that neither Delta or Notch nor any other investigated components of its signalling pathway are likely to be involved in segment addition in onychophorans. We instead suggest that $\mathrm{Dl} / \mathrm{N}$ signalling may be involved in posterior elongation, another conserved function of these genes. We suggest further that the posterior elongation network, rather than classic $\mathrm{Dl} / \mathrm{N}$ signalling, may be in the control of the highly conserved segment polarity gene network and the lower-level pair-rule gene network in onychophorans. Consequently, we believe that the pair-rule gene network and its interaction with $\mathrm{D} / \mathrm{N}$ signalling may have evolved within the arthropod lineage and that $\mathrm{Dl} / \mathrm{N}$
\end{abstract}

Communicated by Siegfried Roth

Electronic supplementary material The online version of this article (doi:10.1007/s00427-016-0529-4) contains supplementary material, which is available to authorized users.

Ralf Janssen

ralf.janssen@geo.uu.se

1 Department of Earth Sciences, Palaeobiology, Uppsala University, Villavägen 16, 75236 Uppsala, Sweden signalling has thus likely been recruited independently for segment addition in different phyla.

Keywords Onychophora $\cdot$ Segmentation $\cdot$ Delta $\cdot$ Notch $\cdot$ Posterior elongation

\section{Introduction}

One of the key features of the arthropods is their segmented body. Most knowledge about the molecular mechanisms underlying the arthropod segmentation process, however, comes from a single model organism, the fly Drosophila melanogaster. In Drosophila, the body becomes segmented more or less simultaneously during development. The quick subdivision of the embryonic body into smaller and smaller units and finally the segments (or parasegments) is achieved by the function of the so-called segmentation genes (Akam 1987; Pick 1998; Sanson 2001). The long-germ developmental mode by which the Drosophila embryo is patterned, however, is highly derived (e.g. Liu and Kaufman 2005; Kimelman and Martin 2012). The great majority of arthropods, including most other insects, add segments one by one or in pairs from a posterior segmentation zone (Chipman et al. 2004; Schoppmeier and Damen 2005a; Janssen 2011, 2014) — so-called short-germ mode development. Most of the segmentation genes that act during Drosophila segmentation also play a conserved or similar role in the segmentation process in short-germ arthropods (e.g. Choe et al. 2006; Choe and Brown 2009; Damen 2002; Damen et al. 2000, 2005; Janssen et al. 2004, 2011a, b). It is therefore widely accepted that arthropod segmentation has evolved only once in the common ancestor of all arthropods, i.e. chelicerates, myriapods, crustaceans and insects (e.g. Peel et al. 2005; Damen 2007). Research on onychophorans, a closely related sister 
group to the arthropods (Campbell et al. 2011), is congruent with this idea and suggests that the common ancestor of onychophorans and arthropods also used a partially conserved genetic program to segment its body (Eriksson et al. 2009; Janssen and Budd 2013; Franke and Mayer 2014; Franke et al. 2015).

Several studies have demonstrated or suggested that Delta/ Notch $(\mathrm{Dl} / \mathrm{N})$ signalling is an important component of the gene regulatory system that underlies segmentation in a wide range of short-germ arthropods including chelicerates (Stollewerk et al. 2003; Schoppmeier and Damen 2005b; Oda et al. 2007), myriapods (Dove and Stollewerk 2003; Kadner and Stollewerk 2004; Chipman and Akam 2008), crustaceans (Williams et al. 2012; Eriksson et al. 2013) and insects (Chesebro et al. 2012). Surprisingly, however, it appears that the involvement of $\mathrm{Dl} / \mathrm{N}$ is not generally conserved (or at least needed) in arthropods to segment their bodies. It has been shown that $\mathrm{Dl} / \mathrm{N}$ has lost its function in segmentation in the holometabolous insects to which Drosophila belongs (Wilson et al. 2010, but Liu 2013), while the role of Dl/N in hemimetabolous insects is still under discussion (Pueyo et al. 2008; Kainz et al. 2011; Mito et al. 2011). This means that D1/ $\mathrm{N}$ signalling was either a component of the ancestral arthropod segmentation mechanism or that it has been recruited several times independently within the arthropod lineages. Despite the still unresolved situation in arthropods, it has even been suggested that $\mathrm{Dl} / \mathrm{N}$ signalling could be a part of a common and conserved segmentation mechanism in all segmented phyla and, thus, in a segmented bilaterian ancestor (e.g. Stollewerk et al. 2003; Pueyo et al. 2008). This is because Dl/N signalling is also an important component of segment (somite) addition in vertebrates and possibly also in annelids (e.g. Pourqui 2003; Rivera et al. 2005; Thamm and Seaver 2008).

Another conserved role of $\mathrm{Dl} / \mathrm{N}$ signalling is its function during posterior elongation (e.g. Oda et al. 2007; Mito et al. 2011; Williams et al. 2012). It is assumed that $\mathrm{Dl} / \mathrm{N}$ signalling may have been an ancestral bilaterian component of posterior elongation more generally than that in segmentation, a function that this gene regulator network may have evolved much later and independently in overtly segmented phyla such as arthropods (reviewed in Chipman 2010).

Expression patterns of onychophoran Notch and Delta genes have previously been described by Oliveira et al. (2013) for a closely related onychophoran, Euperipatoides rowelli, and by Eriksson and Stollewerk (2010) for Euperipatoides kanangrensis. The work of Oliveira et al. (2013) focuses on the development of muscle attachment sides and the analysis of gene expression is restricted to very late embryos. This paper is thus of little help to unravel a potential role of Notch signalling in segmentation. The work by Eriksson and Stollewerk (2010) does not focus on segmentation either, but on the development of the nervous system. Expression patterns that could be associated with a role in segmentation or posterior elongation have not been provided in this publication.

In order to elaborate hypotheses about the origin and evolution of $\mathrm{Dl} / \mathrm{N}$ function during segmentation, it is thus necessary to investigate the expression patterns of key components of Dl/N signalling during segment addition, including the very earliest stages. We therefore studied the embryonic expression profiles of the transmembrane receptor Notch $(\mathrm{N})$, its potential ligands Delta (Dl) and Serrate (Ser) and the Notch-dependent transducing transcription factor Suppressor of Hairless $(\mathrm{Su}(\mathrm{H}))$ in the onychophoran E. kanangrensis. If $\mathrm{Dl} / \mathrm{N}$ signalling is a component of onychophoran segmentation, one would expect canonical Dl/N signalling factors to be expressed in the posterior segmentation zone and in newly formed segments, either ubiquitously or in distinct transverse stripes, as it is the case for these genes in arthropods (Dove and Stollewerk 2003; Kadner and Stollewerk 2004; Chipman and Akam 2008; Schoppmeier and Damen 2005b; Stollewerk et al. 2003). If, however, $\mathrm{Dl} / \mathrm{N}$ signalling is merely involved in posterior elongation, another conserved function of these genes, then one would expect the expression in the posterior tip of the developing embryo.

\section{Methods}

\section{Embryo collection, fixation and staging}

Embryos were collected, fixed and stored for subsequent in situ hybridization experiments as described in Janssen et al. (2015a). Embryos were staged according to Janssen and Budd (2013).

\section{Gene cloning}

Total RNA was isolated from E. kanangrensis embryos of different stages using TRIzol (Invitrogen). Poly-A RNA was extracted from total RNA (PolyATtract mRNA Isolation System III, Promega) and reversely transcribed into cDNA (SuperScript II First-Strand Synthesis System for RT-PCR, Invitrogen). All investigated gene fragments were isolated by means of PCR with gene-specific primers based on a sequenced embryonic transcriptome (Janssen and Budd 2013). In all cases, a first PCR was followed by a second (nested) PCR. Fragments were then cloned into pCR II vectors (TA Cloning Kit Dual Promoter; Invitrogen, Carlsbad, CA, USA). Sequences of isolated gene fragments were determined on a 3100 automated sequencer (Terminator Cycle Sequencing Kit; PerkinElmer Applied Biosystems, Foster City, CA, USA) using BigDye dye terminators version 3.1 (BigDye Terminator Cycle Sequencing Kit; PerkinElmer Applied Biosystems, Foster City, CA, USA). Gene sequences are available under accession numbers LN881709 (Ek-N), LN881710 (Ek-Dl), LN881711 $(E k-S u(H))$ and LN881712 (Ek-Ser). 


\section{Gene orthology}

Identity of the isolated gene fragments was determined previously for Notch and Delta (Eriksson and Stollewerk 2010) (and for the closely related species E. rowelli (Oliveira et al. 2013)). The orthology of the second investigated Notch ligand, Ek-Ser, is proven by the presence of N-terminal N-terminus of Notch ligand (MNNL) and Delta-Serrate ligand (DSL) domains (both shared with Delta) and the Serratespecific C-terminal von Willebrand domain type C (VWC) domain (Marchler-Bauer et al. 2015). The Suppressor of Hairless protein is unique since it contains LAG1, BTD and IPT domains (Marchler-Bauer et al. 2015). Overall, the sequence of this gene is highly conserved among bilaterian animals.

\section{Whole-mount in situ hybridization and nuclear staining}

In situ hybridization was performed as described by Janssen et al. (2015a). Digoxigenin-labelled RNA probes were transcribed from the cloned fragments. E. kanangrensis embryos were hybridized with the probes at $62{ }^{\circ} \mathrm{C}$ for at least $16 \mathrm{~h}$. No protein $\mathrm{K}$ treatment and no additional fixation were performed. Nucleic staining was performed by incubation of the embryos in $1 \mu \mathrm{g} / \mathrm{ml}$ of the fluorescent dye 4',6-diamidino-2phenylindole (DAPI) in phosphate-buffered saline with $0.1 \%$ Tween-20 (PBST) for $40 \mathrm{~min}$.

\section{Data documentation}

Embryos were analysed under a Leica dissection microscope equipped with a Leica DC100 digital camera. The image processing software Adobe Photoshop CS2 (version 9.0.1 for Apple Macintosh) was used for linear corrections of brightness, contrast and colour values in all images.

\section{Results}

\section{Expression patterns}

Our study verifies most of the previously reported gene expression patterns of Euperipatoides Notch and Delta genes (Eriksson and Stollewerk 2010; Oliveira et al. 2013).

In early developmental stages, Euperipatoides Notch (Ek$N$ ) is expressed ubiquitously. Higher levels of expression, however, are in the posterior of the head lobes (compared to the anterior region) and in the posterior pit (Fig. S1A/B). Later, expression disappears from the anterior half of the head lobes and the segment addition zone (Figs. 1a, b and S1B). The posterior pit, however, still expresses $E k-N$ (Figs. 1b, c and S1B). In the anterior hemisphere of the head lobes, $E k-N$ is only expressed in few cells in the developing frontal appendages (Fig. 1c). We assume that these are antennal sense organs (cf. Mayer and Whitington 2009; Eriksson and Stollewerk 2010). In later developmental stages, $E k-N$ is strongly expressed in tissue ventral to the limbs and in the developing limbs (Fig. 1d, e). Expression in the frontal appendages and the trunk appendages is upregulated in single cells or small cell clusters (Fig. 1f). We do not detect a "transverse stripe in the ventral protocerebral primordium" (cf. Eriksson and Stollewerk 2010).

At early stages, all tissues except the saz express Euperipatoides Delta (Ek-Dl) ubiquitously but at low levels (Fig. S1C). Later, expression disappears from the anterior of the head lobes, exactly as it is the case for $N$ (Fig. 2a, b). In the anterior head lobes, only few cells express $E k-D l$ (Fig. 2a, b). This pattern is also comparable to that of $E k-N$, and we assume that expression is in the same cells. The segment addition zone does not express $E k$ - $D l$ (Fig. 2c, d). Like $E k-N$, also $E k-D l$ is expressed in the posterior pit, but the domain of $E k-D l$ is smaller and expression is weaker than that of $E k-N$ (Fig. 2c, d). At later developmental stages, $E k-D l$ is expressed ubiquitously in tissue ventral to the limbs but is upregulated in two distinct domains per segment (Fig. 2e). Comparable expression has been reported for $D l$ in E. rowelli (Oliveira et al. 2013). In the limbs and in tissue dorsal to the limbs, $E k-D l$ is expressed in single cells or small cell clusters (Fig. 2f). We assume that this expression is correlated with the development of sensory organs (e.g. Walker and Tait 2004).

At early developmental stages, Euperipatoides Serrate (Ek-Ser) is expressed in all tissues, except the segment addition zone (Fig. 3a). At stage 11, expression in the head lobes becomes restricted to wedge-shaped domains covering the ventral and posterior regions of the head lobes (Fig. 3b). A few cells in the frontal appendages express Ek-Ser (Fig. 3b). Later, it is expressed in the anterior mesoderm of the limb rudiments and the growing limb buds and inside the head lobes (Fig. 3c, d, f-i). Throughout development, Ek-Ser is weakly expressed around the edges of the posterior pit (Fig. 3b, e).

In early developmental stages, Suppressor of Hairless (Ek$\mathrm{Su}(H))$ is weakly expressed in all tissues except the segment addition zone (Figs. 4a, $\mathrm{d}$ and S1D). Expression is stronger in the posterior and dorsal regions of the head lobes (Fig. 4a) and in some cells in the frontal appendages (Figs. 4b, c and S2). At later developmental stages, the level of expression increases as the segments mature (Fig. 4e). At this point, a single cell within the ectoderm of each walking limb expresses $E k-S u(H)$ as well as a cell dorsal to the base of the slime papillae and the walking limbs (Fig. 4e, f). Expression in the distal region of the limbs disappears (Fig. 4g). 
Fig. 1 Expression of Notch. In all panels, the anterior is to the left. a Lateral view (stage 10). b Ventral view. The posterior end of the embryo is in focus. Arrowhead points to the expression in the tissue surrounding the posterior pit (stage 11). c Ventral view (stage 12). Arrowhead as in b. d Lateral view (stage 14). e Lateral view (stage 19). f Dorsal view of the anterior of the same embryo as shown in e. Arrow points to a single cell in the frontal appendage. $a$ anus, fap frontal appendage, $j$ jaw, $h l$ head lobe, $L$ walking limb, $s a z$ segment addition zone, $s p$ slime papilla

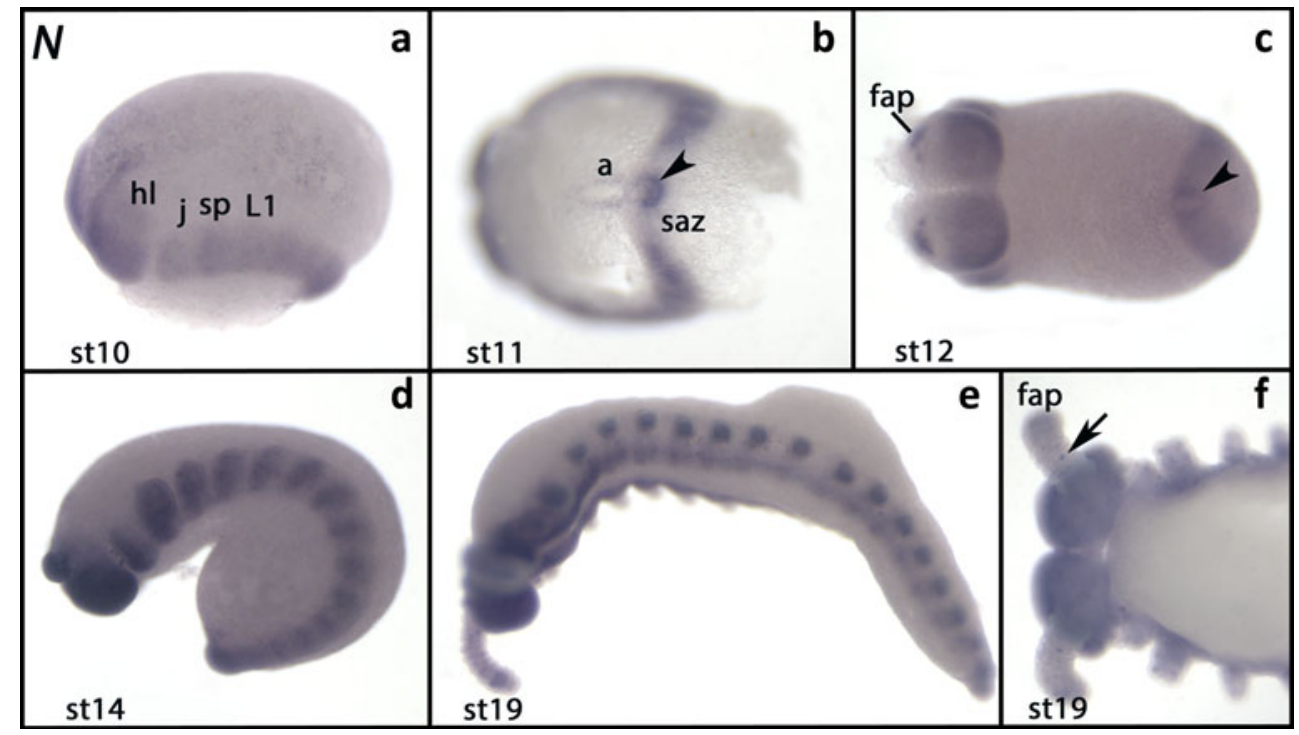

\section{Discussion}

\section{Expression patterns suggest that $\mathrm{Dl} / \mathrm{N}$ signalling is not involved in posterior segment addition in the onychophoran}

No oscillation Three animal phyla classically possess a segmented body (but see also Budd 2001; Scholtz 2002 for discussion of what the meaning of segmentation actually is). These are the vertebrates, the annelids and the arthropods including their close relatives, the onychophorans. In vertebrates, a molecular oscillator functions in posterior segment addition. A characteristic of this mechanism is the dynamic expression of a number of genes in the presomatic mesoderm (the vertebrate segment/somite addition zone) (reviewed in Kageyama et al. 2012). Similar oscillators have long been predicted for arthropods as well, where segmentation genes often show dynamic expression in the segment addition zone. Very recent studies in the beetle Tribolium castaneum finally provided proof that the detected dynamic expression patterns are the result of oscillation, not cell movement (Sarrazin et al. 2012; El-Sherif et al. 2012). Dynamic expression of segmentation gene orthologs in other arthropods implies that this feature, and thus an oscillating mechanism, is conserved in arthropod segmentation (Chipman et al. 2004; Damen et al. 2000, 2005; Chipman and Akam 2008; Janssen et al. 2011a; Kadner and Stollewerk 2004; Pueyo et al. 2008; Eriksson et al. 2013).

Previously, we have analysed a number of onychophoran segmentation gene orthologs, including those genes that cycle in Tribolium, i.e. odd-skipped and even-skipped. None of these genes show any dynamic expression during segment addition in onychophorans (Janssen and Budd 2013).
The analysis of $\mathrm{Dl} / \mathrm{N}$ signalling genes in this study further supports the hypothesis that dynamic gene expression is not present in onychophorans, suggesting that at least partially different mechanisms are used to build the segmented body of arthropods and onychophorans.

No stripes Typically, so-called segmentation genes are, if not expressed in dynamic patterns in the posterior embryo, either expressed ubiquitously or in transverse stripes in the posterior segment addition zone or they are expressed in transverse stripes in newly formed (or forming) segments or somites. The same holds true for the components of the $\mathrm{Dl} / \mathrm{N}$ signalling cascade in animals in which this pathway is (likely) involved in posterior segment addition, such as arthropods, annelids and vertebrates (e.g. Reaume et al. 1992; Palmeirim et al. 1998; Stollewerk et al. 2003; Janssen 2005; Schoppmeier and Damen 2005b; Chipman and Akam 2008; Eriksson et al. 2013; Rivera et al. 2005; Thamm and Seaver 2008).

We find, however, that $N, \mathrm{Dl}, \mathrm{Ser}$ or $\mathrm{Su}(H)$ are expressed neither in the anterior of the segment addition zone nor in transverse stripes in newly forming segments. Therefore, we conclude that the core of $\mathrm{D} 1 / \mathrm{N}$ signalling is not involved in onychophoran segmentation.

No downstream patterning Pair-rule gene orthologs (PRGs) function downstream of (or level with the) $\mathrm{Dl} / \mathrm{N}$ signalling in arthropods as shown for a spider (Chelicerata) and a water flea (Crustacea) (Stollewerk et al. 2003; Schoppmeier and Damen 2005b; Eriksson et al. 2013) and as suggested by dynamic gene expression in a variety of arthropods (Damen et al. 2000, 2005; Dove and Stollewerk 2003; Kadner and Stollewerk 2004; Janssen 2005, 2011; Pueyo et al. 2008; 


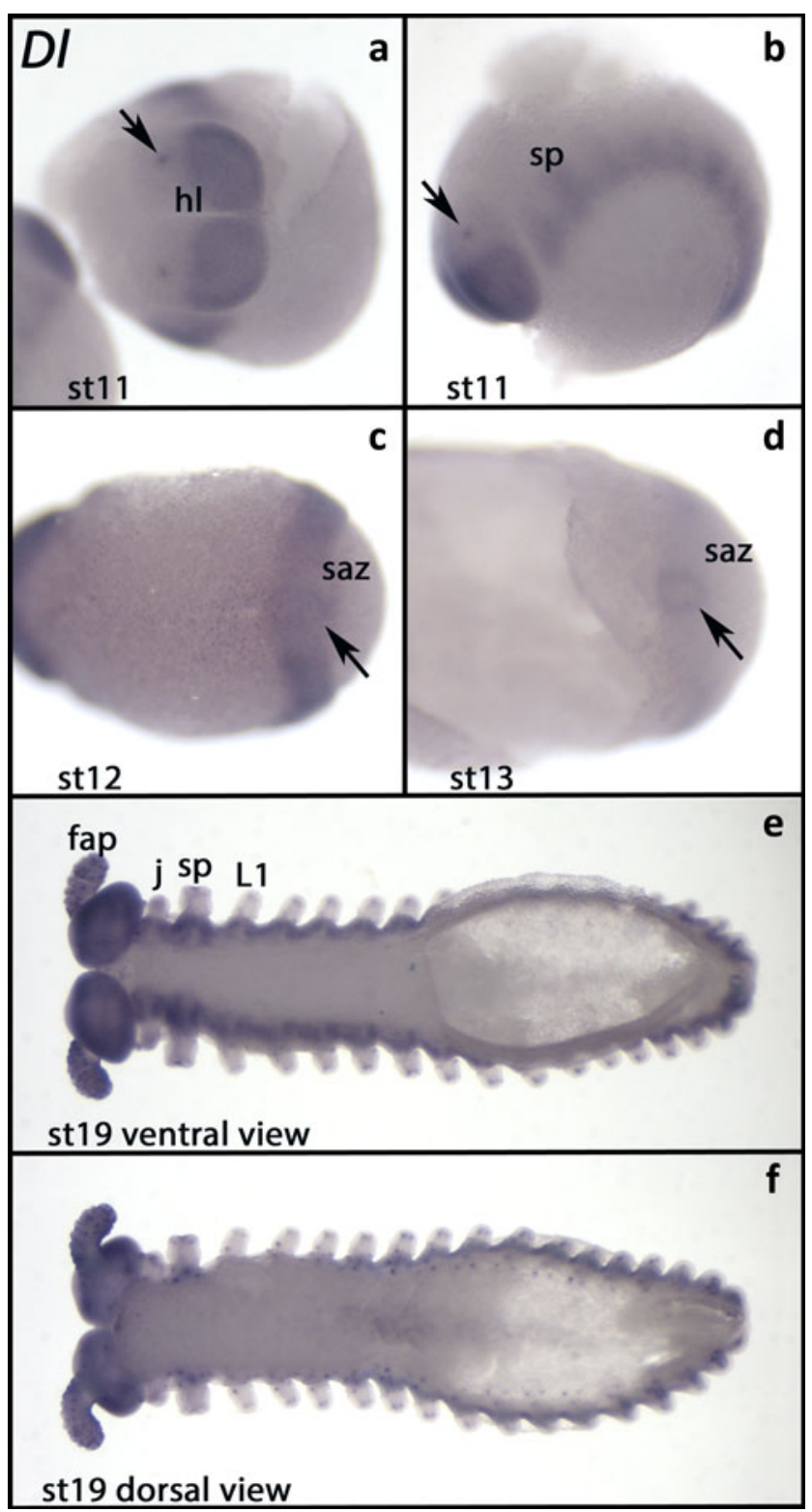

Fig. 2 Expression of Delta. In all panels, the anterior is to the left. a View of the anterior of the embryo (stage 11). Arrow points to a spot of expression in the primordium of the frontal appendage. b The same embryo as in a (lateral view). Arrow as in a. c Ventral view. Arrow points to the weak expression surrounding the posterior pit. d Posterior part of an embryo (ventral view, stage 13). Arrow as in c. e Ventral view (stage 19). f The same embryo as in e (dorsal view). Abbreviations as in Fig. 1

Chipman and Akam 2008; Janssen et al. 2011a, 2012; Eriksson et al. 2013).

The situation in vertebrates is similar in that $\mathrm{Dl} / \mathrm{N}$ signalling is coupled to hairy-related genes (Davis and Turner 2001; Kageyama et al. 2012). In Drosophila, hairy acts as a primary PRG and thus plays an important role in the segmentation process. The function of hairy-related genes is likely conserved in other arthropods as well (Damen et al. 2000; Pueyo et al. 2008; Chipman and Akam 2008; Janssen et al. 2011a; Eriksson et al. 2013; but see Choe et al. 2006; Aranda et al. 2008 for studies that suggest that hairy-related genes have no (or have lost their) function in trunk segmentation).

We have previously investigated the expression of three hairy-related genes (hairy/Hes, Hes 2 and Hes 3 ) in E. kanangrensis. Neither of these genes nor any other pairrule gene ortholog is likely involved in the segmentation process, since neither of these genes, except even-skipped (eve), is expressed in the segment addition zone (Janssen and Budd 2013). These data further collaborate with our hypothesis that $\mathrm{D} / \mathrm{N}$ signalling is not part of the onychophoran segmentation process.

\section{Posterior elongation vs posterior segment addition}

Posterior segment addition is correlated with the elongation of the anterior-posterior axis. Recent work on this topic has revealed a number of conserved genetic factors such as brachyury (bra), even-skipped (eve), caudal (cad), the Wnt genes and $\mathrm{Dl} / \mathrm{N}$ signalling genes that are involved in the posterior elongation in bilaterian animals (van den Akker et al. 2002; Lohnes 2003; Copf et al. 2004; Chawengsaksophak et al. 2004; Shimizu et al. 2005; de Rosa et al. 2005, Beermann et al. 2011; Martin and Kimelman 2008, 2009; Mito et al. 2011; Williams et al. 2012; Chesebro et al. 2012).

The conserved expression patterns of onychophoran bra (Janssen et al. 2015b), eve (Janssen and Budd 2013), cad (Janssen and Budd 2013; Janssen et al. 2015b) and expression of some Wnt genes such as $w g / W n t 1, W n t 5$ and Wnt11 as indicators of Wnt signalling (Eriksson et al. 2009; Hogvall et al. 2014) strongly imply that these factors also play a role in the posterior elongation in onychophorans.

Despite the fact that $D l / N$ signalling genes are not expressed in a segmentation gene-like fashion (discussed above), we find that at least $N, D l$ and $S e r$ are indeed expressed in the posterior pit region at the very posterior pole of the developing onychophoran embryo. This implies that these genes, and thus $\mathrm{Dl} / \mathrm{N}$ signalling, are likely involved in the posterior elongation in onychophorans as well.

\section{What controls conserved segmental patterns of segment polarity genes and pairberry (pby) in onychophorans?}

In Drosophila, the segment polarity genes (SPGs) and the tertiary PRG paired ( $p r d$ ) are under control of upstream acting PRGs. The PRGs are under control of the gap genes, which in turn are under control of inter alia, the posterior determinant caudal (cad) (reviewed in Pankratz and Jäckle 1993).

Despite the different modes of development in most other arthropods than Drosophila (long-germ vs short-germ development), the role of $\mathrm{cad}$ as a posterior determinant appears to be conserved (Shinmyo et al. 2005; Olesnicky et al. 2006; Nakao 2012; Copf et al. 2003, 2004) as well as the function 
Fig. 3 Expression of Serrate. In all panels, the anterior is to the left. a Lateral view (stage 10). b Ventral view (stage 11).

Arrowheads mark the expression inside the frontal appendages. $\mathbf{b}^{\prime}$ A DAPI counterstaining of the same embryo as shown in b. c Lateral view (stage 15). Asterisk marks the expression inside the head lobe. $\mathbf{d}$ Anterior of an embryo (ventral view, stage 15). Arrows mark the expression in the mesoderm of the slime papillae. $\mathbf{e}$ Posterior end of an embryo (stage 16). Arrow points to the expression in the mesoderm of the segment addition zone. f Lateroventral view (stage 18). Asterisk as in c. $\mathbf{g}$ The same embryo as in $\mathbf{f}$ (ventral view). Asterisks as in $\mathbf{c .} \mathbf{h}$ Ventral view (stage 16). Close up on walking limbs. Expression in the anterior mesoderm. i Ventral view (stage 14). Close up on walking limb bearing segments. Expression in the mesoderm. Abbreviations as in Fig. 1

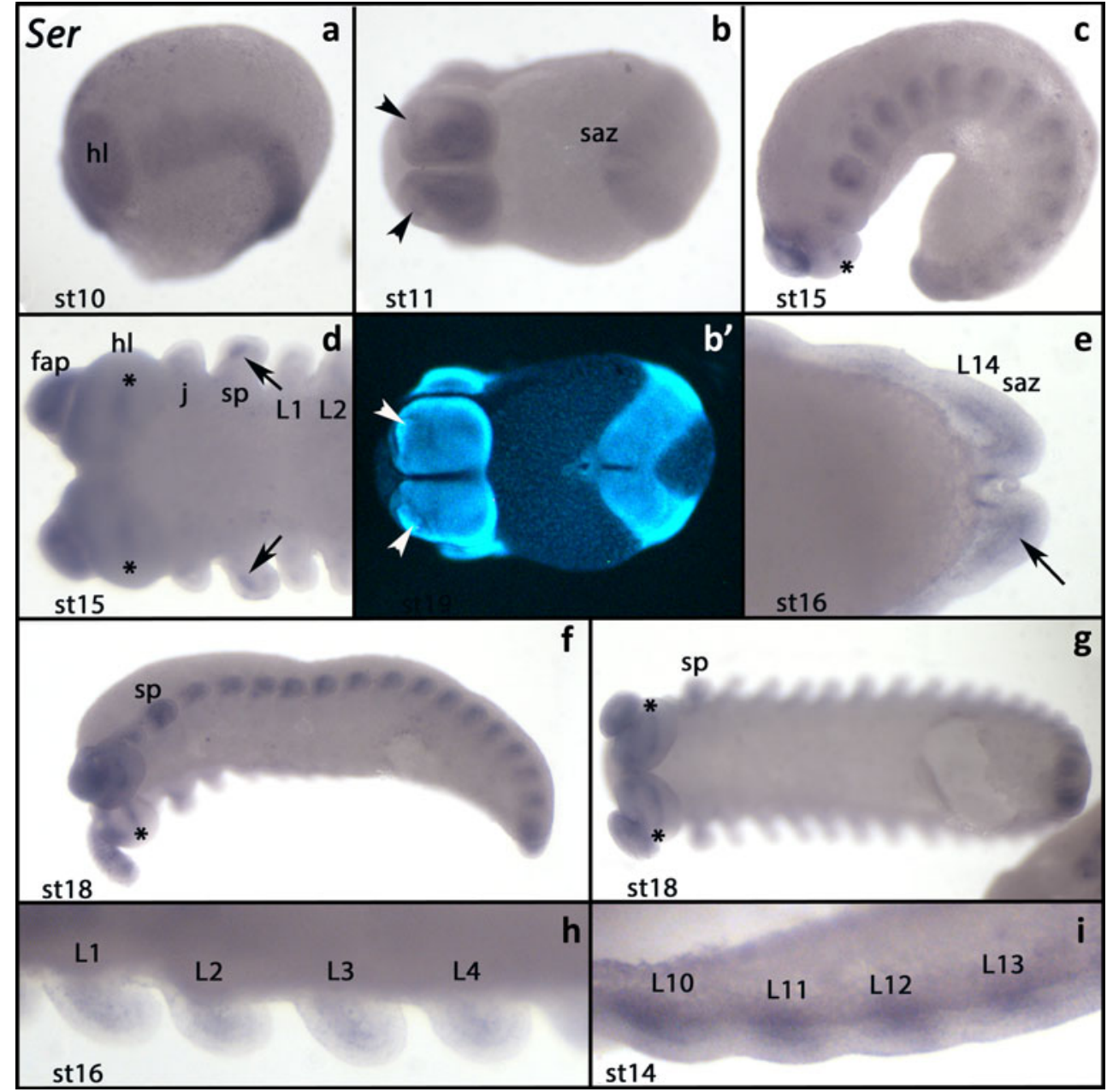

of SPGs (Ingham 1991; Janssen et al. 2004; Simonnet et al. 2004; Farzana and Brown 2008; O’Donnell and Jockusch 2010). Gene expression pattern analysis and some functional studies also imply that PRGs, and here especially the primary PRGs, are generally involved in arthropod segment addition and likely work level with the Dl/N signalling (e.g. Damen

Fig. 4 Expression of Suppressor of Hairless. In all panels, the anterior is to the left. a Ventral view (stage 11). b Lateral view (stage 13). c Close up on a frontal appendage of the embryo shown in b. $\mathbf{d}$ Close up on the posterior end of an embryo (ventral view, stage 14). e Lateral view (stage 16). Arrow points to the expression in the eye. $\mathbf{f}$ Close up of the embryo shown in e (lateral view). Arrows point to the dotlike expression dorsal to the limbs. Arrowheads mark the dotlike expression in the walking limbs. g Ventral view. Note that the tips of the limbs do not express $\mathrm{Su}(H)$. Abbreviations as in Fig. 1

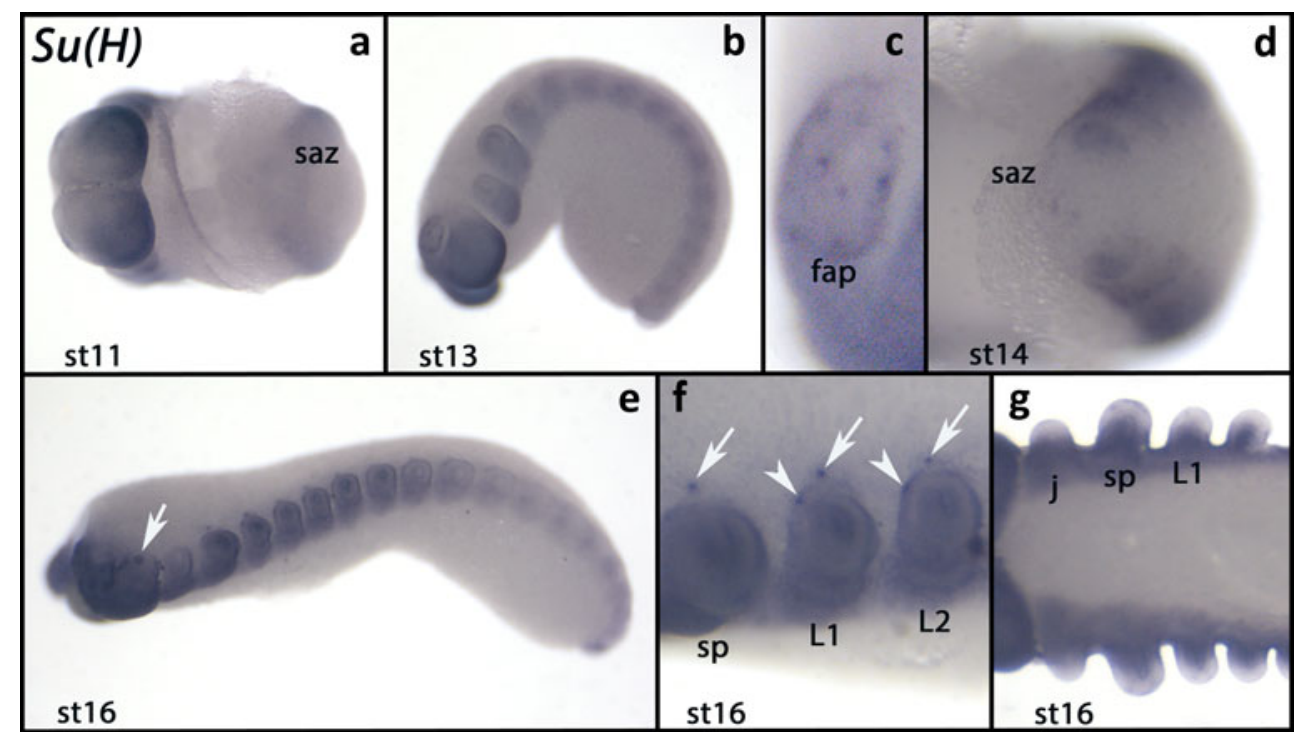


a Arthropoda: Drosophila



cad

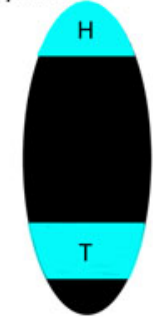

GAP

b Arthropoda: Generalized

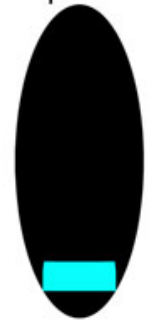

cad, Wnt

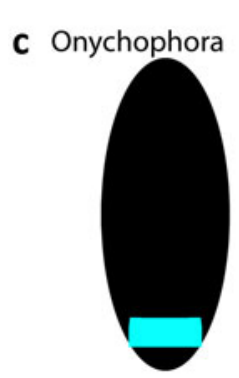

cad, Wnt

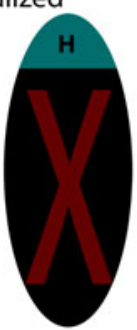

GAP

(?)

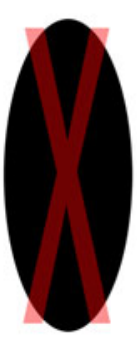

GAP

(?)

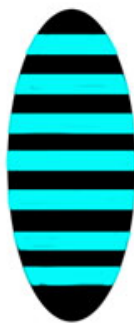

PRG

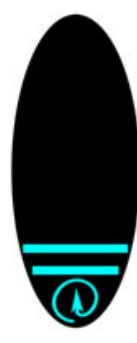

PRG

$D I / N$

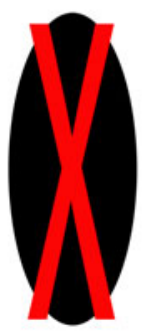

PRG

$D I / N$

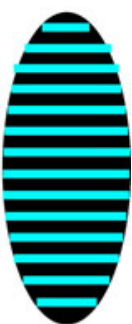

SPG
Fig. 5 Evolution of segmentation gene systems in onychophorans and arthropods. In the long-germ insect Drosophila, segmentation is under control of the segmentation gene cascade (reviewed in Pankratz and Jäckle 1990). The gap gene system likely evolved in the lineage leading to Drosophila (see supplementary text for further information). In onychophorans, neither the gap gene system (see supplementary text for further information) nor the downstream acting pair-rule gene (PRG) system is conserved. Dynamic expression of D1/ $\mathrm{N}$ signalling genes is not present either. It is thus unclear how exactly the conserved patterns of the segment polarity genes $(S P G s)$ are established in onychophorans. Possibly, SPGs are under direct control of the conserved posterior patterning system ( $c a d, W n t)$. Black ovals represent embryos. Gene expression is in light blue. Red $X$ indicates the loss of function during segmentation. Red $X$ with decreased opacity indicates a somewhat unclear situation (in Arthropoda) and an incomplete data set (in Onychophora). Blue circular arrow indicates the dynamic gene expression in the segment addition zone. cad caudal, Dl/N Delta/Notch signalling genes, GAP gap genes, $H$ head, $P R G$ pair-rule genes, $S P G$ segment polarity genes, $T$ trunk

et al. 2000, 2005; Schoppmeier and Damen 2005a; Choe et al. 2006; Choe and Brown 2007; Chipman and Akam 2008; Janssen et al. 2011a). Gap gene-based trunk segmentation likely evolved within the insect lineage (Peel and Akam 2003; see additional text in the supplementary section for more information). In the beetle Tribolium, an insect with the less-derived short-germ mode of development, for example, the function of the gap genes is less dominant than in Drosophila (reviewed in Jaeger 2011), and here, PRGs are partially under direct control of cad (El-Sherif et al. 2014).

In onychophorans, gene expression analysis suggests that the primary PRGs as identified in Drosophila and Tribolium (i.e. even-skipped (eve), runt (run), hairy ( $h$ ) and odd-skipped $(o d d)$ ) are not directly involved in the regulation of the highly conserved segment polarity gene network (Janssen and Budd 2013), and neither is the Dl/N pathway, as demonstrated in the current article.

Based on the accumulated gene expression data, we therefore suggest that the posterior elongation system and its likely conserved components (e.g. cad, Wnt signalling (Chesebro et al. 2012)) may be in direct control of pby and the segment polarity gene network in onychophorans and that $\mathrm{PRG} / \mathrm{Dl} / \mathrm{N}$ mediated segmentation may have evolved in the arthropod lineage (Fig. 5).

In order to test this hypothesis, however, it would be important to establish functional methods to analyse gene function in onychophorans, which are currently lacking.

Acknowledgments This work has been supported by the Swedish Research Council (grant to GEB and RJ). We gratefully acknowledge the support of the New South Wales Government Department of Environment and Climate Change by provision of a permit SL100159 to collect onychophorans at the Kanangra-Boyd National Park and to the Australian Government Department of the Environment, Water, Heritage and the Arts for export permits WT2009-4598 and WT2012-4704. We thank Jean Joss, Rolf Ericsson, Robyn Stutchbury and, especially, Noel Tait for their help during the onychophoran collection. Nico Posnien and Alistair McGregor helped with the analysis of the onychophoran transcriptome.

Open Access This article is distributed under the terms of the Creative Commons Attribution 4.0 International License (http:// creativecommons.org/licenses/by/4.0/), which permits unrestricted use, distribution, and reproduction in any medium, provided you give appropriate credit to the original author(s) and the source, provide a link to the Creative Commons license, and indicate if changes were made.

\section{References}

Akam M (1987) The molecular basis for metameric pattern in the Drosophila embryo. Development 101:1-22

Aranda M, Marques-Souza H, Bayer T, Tautz D (2008) The role of the segmentation gene hairy in Tribolium. Dev Genes Evol 218:465477

Beermann A, Pruehs R, Lutz R, Schroeder R (2011) A context-dependent combination of Wnt receptors controls axis elongation and leg development in a short germ insect. Development 138:2793-2805

Budd GE (2001) Why are arthropods segmented? Evol Dev 3:332-342 
Campbell LI, Rota-Stabelli O, Edgecombe GD, Marchioro T, Longhorn SJ, Telford MJ, Philippe H, Rebecchi L, Peterson KJ, Pisani D (2011) MicroRNAs and phylogenomics resolve the relationships of Tardigrada and suggest that velvet worms are the sister group of Arthropoda. Proc Natl Acad Sci U S A 108:15920-15924

Chawengsaksophak K, de Graaff W, Rossant J, Deschamps J, Beck F (2004) Cdx2 is essential for axial elongation in mouse development. Proc Natl Acad Sci U S A 101:7641-7645

Chesebro JE, Pueyo JI, Couso JP (2012) Interplay between a Wntdependent organizer and the Notch segmentation clock regulates posterior development in Periplaneta americana. Biol Open 2: $227-237$

Chipman AD, Arthur W, Akam M (2004) A double segment periodicity underlies segment generation in centipede development. Curr Biol $14: 1250-1255$

Chipman AD (2010) Parallel evolution of segmentation by co-option of ancestral gene regulatory networks. Bioessays 32(1):60-70. doi: 10 . 1002/bies.200900130

Chipman AD, Akam M (2008) The segmentation cascade in the centipede Strigamia maritima: involvement of the Notch pathway and pair-rule gene homologues. Dev Biol 319:160-169

Choe CP, Miller SC, Brown SJ (2006) A pair-rule gene circuit defines segments sequentially in the short-germ insect Tribolium castaneum. Proc Natl Acad Sci U S A 103:6560-6564

Choe CP, Brown SJ (2007) Evolutionary flexibility of pair-rule patterning revealed by functional analysis of secondary pair-rule genes, paired and sloppy-paired in the short-germ insect, Tribolium castaneum. Dev Biol 302:281-294

Choe CP, Brown SJ (2009) Genetic regulation of engrailed and wingless in Tribolium segmentation and the evolution of pair-rule segmentation. Dev Biol 325:482-491

Copf T, Rabet N, Celniker SE, Averof M (2003) Posterior patterning genes and the identification of a unique body region in the brine shrimp Artemia franciscana. Development 130:5915-5927

Copf T, Schroeder R, Averof M (2004) Ancestral role of caudal genes in axis elongation and segmentation. Proc Natl Acad Sci U S A 101: 17711-17715

Damen WG, Weller M, Tautz D (2000) Expression patterns of hairy, even-skipped, and runt in the spider Cupiennius salei imply that these genes were segmentation genes in a basal arthropod. Proc Natl Acad Sci U S A 97:4515-4519

Damen WG (2002) Parasegmental organization of the spider embryo implies that the parasegment is an evolutionary conserved entity in arthropod embryogenesis. Development 129:1239-1250

Damen WG, Janssen R, Prpic NM (2005) Pair rule gene orthologs in spider segmentation. Evol Dev 7:618-628

Damen WG (2007) Evolutionary conservation and divergence of the segmentation process in arthropods. Dev Dyn 236:1379-1391

Davis RL, Turner DL (2001) Vertebrate hairy and Enhancer of split related proteins: transcriptional repressors regulating cellular differentiation and embryonic patterning. Oncogene 20:8342-8357

de Rosa R, Prud'homme B, Balavoine G (2005) Caudal and even-skipped in the annelid Platynereis dumerilii and the ancestry of posterior growth. Evol Dev 7:574-587

Dove H, Stollewerk A (2003) Comparative analysis of neurogenesis in the myriapod Glomeris marginata (Diplopoda) suggests more similarities to chelicerates than to insects. Development 130:2161-2171

El-Sherif E, Averof M, Brown SJ (2012) A segmentation clock operating in blastoderm and germband stages of Tribolium development. Development 139:4341-4346

El-Sherif E, Zhu X, Fu J, Brown SJ (2014) Caudal regulates the spatiotemporal dynamics of pair-rule waves in Tribolium. PLoS Genet 10: e1004677

Eriksson BJ, Tait NN, Budd GE, Akam M (2009) The involvement of engrailed and wingless during segmentation in the onychophoran
Euperipatoides kanangrensis (Peripatopsidae: Onychophora) (Reid 1996). Dev Genes Evol 219:249-264

Eriksson BJ, Stollewerk A (2010) The morphological and molecular processes of onychophoran brain development show unique features that are neither comparable to insects nor to chelicerates. Arthropod Struct Dev 39:478-490

Eriksson BJ, Ungerer P, Stollewerk A (2013) The function of Notch signalling in segment formation in the crustacean Daphnia magna (Branchiopoda). Dev Biol 383:321-330

Farzana L, Brown SJ (2008) Hedgehog signalling pathway function conserved in Tribolium segmentation. Dev Genes Evol 218:181-192

Franke FA, Mayer G (2014) Controversies surrounding segments and parasegments in onychophora: insights from the expression patterns of four "segment polarity genes" in the peripatopsid Euperipatoides rowelli. PLoS ONE 9:e114383

Franke FA, Schumann I, Hering L, Mayer G (2015) Phylogenetic analysis and expression patterns of Pax genes in the onychophoran Euperipatoides rowelli reveal a novel bilaterian Pax subfamily. Evol Dev 17:3-20

Hogvall M, Schoenauer A, Budd GE, McGregor AP, Posnien N, Janssen $\mathrm{R}$ (2014) Analysis of the Wnt gene repertoire in an onychophoran provides new insights into the evolution of segmentation. Evodevo $5: 14$

Ingham PW (1991) Segment polarity genes and cell patterning within the Drosophila body segment. Curr Opin Genet Dev 1:261-267

Jaeger J (2011) The gap gene network. Cell Mol Life Sci 68:243-274

Janssen R, Prpic NM, Damen WG (2004) Gene expression suggests decoupled dorsal and ventral segmentation in the millipede Glomeris marginata (Myriapoda: Diplopoda). Dev Biol 268:89104

Janssen R (2005) Untersuchungen zur molekularen Grundlage der Segmentbildung im Saftkugler Glomeris marginata (Myriapoda: Diplopoda). [Molecular basis of segmentation in the millipede Glomeris marginata (Myriapoda: Diplopoda).] PhD Thesis, University of Cologne, Cologne, Germany

Janssen R (2011) Diplosegmentation in the pill millipede Glomeris marginata is the result of dorsal fusion. Evol Dev 13:477-487

Janssen R, Budd GE, Prpic NM, Damen WG (2011a) Expression of myriapod pair rule gene orthologs. Evodevo 2:5

Janssen R, Budd GE, Damen WG (2011b) Gene expression suggests conserved mechanisms patterning the heads of insects and myriapods. Dev Biol 357:64-72

Janssen R, Damen WG, Budd GE (2012) Expression of pair rule gene orthologs in the blastoderm of a myriapod: evidence for pair rulelike mechanisms? BMC Dev Biol 12:15

Janssen R, Budd GE (2013) Deciphering the onychophoran 'segmentation gene cascade': gene expression reveals limited involvement of pair rule gene orthologs in segmentation, but a highly conserved segment polarity gene network. Dev Biol 382:224-234

Janssen R (2014) Gene expression suggests double-segmental and singlesegmental patterning mechanisms during posterior segment addition in the beetle Tribolium castaneum. Int J Dev Biol 58:343-347

Janssen R, Jörgensen M, Prpic NM, Budd GE (2015a) Aspects of dorsoventral and proximo-distal limb patterning in onychophorans. Evol Dev 17:21-33

Janssen R, Jörgensen M, Lagebro L, Budd GE (2015b). Fate and nature of the onychophoran mouth-anus furrow and its contribution to the blastopore. Proc R Soc B 282. doi: 10.1098/rspb.2014.2628

Kadner D, Stollewerk A (2004) Neurogenesis in the chilopod Lithobius forficatus suggests more similarities to chelicerates than to insects. Dev Genes Evol 214:367-379

Kainz F, Ewen-Campen B, Akam M, Extavour CG (2011) Notch/Delta signalling is not required for segment generation in the basally branching insect Gryllus bimaculatus. Development 138:50155026 
Kageyama R, Niwa Y, Isomura A, Gonzalez A, Harima Y (2012) Oscillatory gene expression and somitogenesis. Wiley Interdiscip Rev Dev Biol 1:629-641

Kimelman D, Martin BL (2012) Anterior-posterior patterning in early development: three strategies. Wiley Interdiscip Rev Dev Biol 1: 253-266

Liu W (2013) Bmdelta phenotype implies involvement of Notch signalling in body segmentation and appendage development of silkworm, Bombyx mori. Arthropod Struct Dev 42:143-151

Liu PZ, Kaufman TC (2005) Short and long germ segmentation: unanswered questions in the evolution of a developmental mode. Evol Dev 7:629-646

Lohnes D (2003) The Cdx1 homeodomain protein: an integrator of posterior signalling in the mouse. BioEssays 25:971-980

Marchler-Bauer A, Derbyshire MK, Gonzales NR, Lu S, Chitsaz F, Geer LY, Geer RC, He J, Gwadz M, Hurwitz DI, Lanczycki CJ, Lu F, Marchler GH, Song JS, Thanki N, Wang Z, Yamashita RA, Zhang D, Zheng C, Bryant SH (2015) CDD: NCBI's conserved domain database. Nucleic Acids Res 43(Database issue):D222-226

Martin BL, Kimelman S (2008) Regulation of canonical Wnt signalling by Brachyury is essential for posterior mesoderm formation. Dev Cell 15:121-133

Martin BL, Kimelman D (2009) Wnt signalling and the evolution of embryonic posterior development. Curr Biol 19:R215-R219

Mayer G, Whitington PM (2009) Neural development in Onychophora (velvet worms) suggests a step-wise evolution of segmentation in the nervous system of Panarthropoda. Dev Biol 335: 263-275

Mito T, Shinmyo Y, Kurita K, Nakamura T, Ohuchi H, Noji S (2011) Ancestral functions of Delta/Notch signalling in the formation of body and leg segments in the cricket Gryllus bimaculatus. Development 138:3823-3833

Nakao H (2012) Anterior and posterior centers jointly regulate Bombyx embryo body segmentation. Dev Biol 371:293-301

O'Donnell BC, Jockusch EL (2010) The expression of wingless and engrailed in developing embryos of the mayfly Ephoron leukon (Ephemeroptera: Polymitarcyidae). Dev Genes Evol 220:11-24

Oda H, Nishimura O, Hirao Y, Tarui H, Agata K, Akiyama-Oda Y (2007) Progressive activation of Delta-Notch signalling from around the blastopore is required to set up a functional caudal lobe in the spider Achaearanea tepidariorum. Development 134:2195-2205

Olesnicky EC, Brent AE, Tonnes L, Walker M, Pultz MA, Leaf D, Desplan C (2006) A caudal mRNA gradient controls posterior development in the wasp Nasonia. Development 133:3973-3982

Oliveira IS, Tait NN, Strübing I, Mayer G (2013) The role of ventral and preventral organs as attachment sites for segmental limb muscles in Onychophora. Front Zool 10:73

Palmeirim I, Dubrulle J, Henrique D, Ish-Horowicz D, Pourquie O (1998) Uncoupling segmentation and somitogenesis in the chick presomitic mesoderm. Dev Genet 23:77-85

Pankratz MJ, Jäckle H (1990) Making stripes in the Drosophila embryo. Trends Genet 6(9):287-92

Pankratz MJ, Jäckle H (1993) Blastoderm segmentation. In: Bate M, Martinez Arias A (eds) The development of Drosophila melanogaster. Cold Spring Harbor Laboratory Press, Cold Spring Harbor, pp 467-516

Peel A, Akam M (2003) Evolution of segmentation: rolling back the clock. Curr Biol 13:R708-710
Peel AD, Chipman AD, Akam M (2005) Arthropod segmentation: beyond the Drosophila paradigm. Nat Rev Genet 6:905-916

Pick L (1998) Segmentation: painting stripes from flies to vertebrates. Dev Genet 23:1-10

Pourqui O (2003) The segmentation clock: converting embryonic time into spatial pattern. Science 301:328-330

Pueyo JI, Lanfear R, Couso JP (2008) Ancestral Notch-mediated segmentation revealed in the cockroach Periplaneta americana. Proc Natl Acad Sci U S A 105:16614-16619

Reaume AG, Conlon RA, Zirngibl R, Yamaguchi TP, Rossant J (1992) Expression analysis of a Notch homologue in the mouse embryo. Dev Biol 154:377-387

Rivera AS, Gonsalves FC, Song MH, Norris BJ, Weisblat DA (2005) Characterization of Notch-class gene expression in segmentation stem cells and segment founder cells in Helobdella robusta (Lophotrochozoa; Annelida; Clitellata; Hirudinida; Glossiphoniidae). Evol Dev 7:588-599

Sanson B (2001) Generating patterns from fields of cells. Examples from Drosophila segmentation. EMBO Rep 2:1083-1088

Sarrazin AF, Peel AD, Averof M (2012) A segmentation clock with twosegment periodicity in insects. Science 336:338-341

Scholtz G (2002) The Articulata hypothesis - or what is a segment? Org Div Evol 2:197-215

Schoppmeier M, Damen WG (2005a) Expression of Pax group III genes suggests a single-segmental periodicity for opisthosomal segment patterning in the spider Cupiennius salei. Evol Dev 7:160-169

Schoppmeier M, Damen WG (2005b) Suppressor of Hairless and Presenilin phenotypes imply involvement of canonical Notchsignalling in segmentation of the spider Cupiennius salei. Dev Biol 280:211-224

Shimizu T, Bae YK, Muraoka O, Hibi M (2005) Interaction of Wnt and caudal-related genes in zebrafish posterior body formation. Dev Biol 279:125-141

Shinmyo Y, Mito T, Matsushita T, Sarashina I, Miyawaki K, Ohuchi H, Noji S (2005) caudal is required for gnathal and thoracic patterning and for posterior elongation in the intermediate germband cricket Gryllus bimaculatus. Mech Dev 122:231-239

Simonnet F, Deutsch J, Queinnec E (2004) hedgehog is a segment polarity gene in a crustacean and a chelicerate. Dev Genes Evol 214:537545

Stollewerk A, Schoppmeier M, Damen WG (2003) Involvement of Notch and Delta genes in spider segmentation. Nature 423:863-865

Thamm K, Seaver EC (2008) Notch signalling during larval and juvenile development in the polychaete annelid Capitella sp. I. Dev Biol 320: 304-318

van den Akker E, Forlani S, Chawengsaksophak K, de Graaff W, Beck F, Meyer BI, Deschamps J (2002) Cdx1 and Cdx2 have overlapping functions in anteroposterior patterning and posterior axis elongation. Development 129:2181-2193

Walker MH, Tait NN (2004) Studies on embryonic development and the reproductive cycle in ovoviviparous Australian Onychophora (Peripatopsidae). J Zool 264:333-354

Williams T, Blachuta B, Hegna TA, Nagy LM (2012) Decoupling elongation and segmentation: notch involvement in anostracan crustacean segmentation. Evol Dev 14:372-382

Wilson MJ, McKelvey BH, van der Heide S, Dearden PK (2010) Notch signalling does not regulate segmentation in the honeybee, Apis mellifera. Dev Genes Evol 220:179-190 